\title{
FAKTOR-FAKTOR YANG BERHUBUNGAN DENGAN PERILAKU BERISIKO PADA REMAJA
}

\author{
Mia Wahdini ${ }^{1}$, Noormarina Indraswari², Ari Indra Susanti ${ }^{*}$, Budi Sujatmiko ${ }^{4}$ \\ 1Perwakilan BKKBN Provinsi Jawa Barat \\ 2,3,4Departemen IImu Kesehatan Masyarakat, Fakultas Kedokteran, Universitas Padjadjaran \\ *Korespondensi \\ email: ari.indra@unpad.ac.id
}

\section{ABSTRACT FACTORS RELATING TO BEHAVIOR RISK IN TEENS}

Background: Physical and psychological development can lead adolescence to do risky behaviors, such as having premarital sex and using drugs. These behaviours are influenced by sociodemographic factor, knowledge, family function, and source of information on adolescent reproductive health.

Objective: This study aimed to investigate risk factors associated with risky behaviors in adolescents (1524 years old and unmarried) in West Java Province.

Methods: Factors investigated in this study are: predisposing factor, such as age, sex, and knowledge; enabling factor, such as place of residency, economic status, and access to information; reinforcing factor, such as family. Secondary data from Survey of Population Performance and Accountability, Family Planning, and Family Development 2018 is used in this study. Data is analysed using descriptive and inferential statistics (bivariate and multivariate logistic regression).

Results: Older adolescent, being male, live in urban area, whose mother is $\geq 60$ years are more exposed to risky behavior. Adolescents who have higher educational level, more awareness in adolescent reproductive health, and whose parents are well informed towards adolescent reproductive health are associated with reduction of risky behavior.

Conslusion: Factors related to risky behaviour in adolescents are age, sex, adolescent's level of education, mother's age, and exposure to adolescent reproductive health.

Suggestion the government needs to initiate and improve programs related to KRR

Keywords: Adolescent, Risk behavior, Premarital sex, Drugs, Adolescent reproductive health

\section{ABSTRAK}

Latar belakang: Perkembangan fisik dan psikis dapat memicu remaja untuk melakukan perilaku berisiko seperti melakukan seks pranikah dan mengonsumsi narkoba. Perilaku ini dipengaruhi oleh faktor sosiodemografi, pengetahuan remaja, fungsi keluarga, dan sumber informasi tentang kesehatan reproduksi remaja (KRR).

Tujuan: Penelitian ini bertujuan untuk mengetahui faktor-faktor yang berhubungan dengan perilaku berisiko pada remaja, usia 15-24 tahun, dan belum menikah di Jawa Barat.

Metode: Faktor-faktor yang diteliti terdiri dari: faktor yang berasal dari diri remaja (predisposisi), misalnya, usia, jenis kelamin, dan pengetahuan; faktor pendorong (enabling), contohnya tempat tinggal, status ekonomi, dan akses informasi; faktor penguat (reinforcing), yaitu keluarga. Penelitian ini menggunakan data Survei Kinerja dan Akuntabilitas Program (SKAP) Kependudukan, Keluarga Berencana, dan Pembangunan Keluarga tahun 2018. Data dianalisis secara deskriptif dan inferensial menggunakan bivariat dan multivariat regresi logistik.

Hasil: Profil remaja yang lebih tua, berjenis kelamin laki-laki, tinggal di perkotaan, memiliki ibu yang berusia $\geq 60$ tahun lebih rentan terhadap perilaku berisiko. Sedangkan remaja berpendidikan menengah tinggi, pengetahuan KRR yang lebih baik, dan memiliki orang tua yang lebih banyak terpapar informasi KRR berpengaruh signifikan terhadap penurunan perilaku berisiko.

Kesimpulan: Faktor-faktor yang berhubungan dengan perilaku berisiko pada remaja adalah umur, jenis kelamin, tempat tinggal, pendidikan remaja, usia ibu, dan paparan pengetahuan KRR.

Saran pemerintah perlu menginisiasi dan memperbaiki program yang berkaitan dengan KRR

Kata kunci: Remaja, perilaku berisiko, Seks pranikah, Narkoba, Kesehatan reproduksi remaja 


\section{JKM (Jurnal Kebidanan Malahayati),Vol 7,No.2.April 2021, ISSN (Print) 2476-8944 ISSN (Online) 2579-762X, Hal 177-184}

\section{PENDAHULUAN}

Remaja mengalami perkembangan fisik (organ reproduksi primer maupun sekunder), hormonal, kepribadian, sosialisasi, inteligensi, serta emosional. Perubahan tersebut mengakibatkan remaja ingin mencari jati diri, sehingga cenderung melakukan perilaku berisiko (Anas, 2010). Menurut sensus penduduk tahun 2010, remaja di Indonesia menyumbang sebanyak $26,7 \%$ dari total jumlah penduduk. Hal ini menjadi tantangan bagi pemerintah karena sebahai generasi penerus bangsa, remaja harus disiapkan menjadi generasi sehat dan berkualitas. Provinsi Jawa Barat memiliki persebaran penduduk dengan usia 15-24 tahun sebesar 20\% (Badan Kependudukan dan Keluarga Berencana Nasional, 2011). Tingginya jumlah remaja pada populasi berpotensi pada timbulnya masalah sosial di Jawa Barat, sehingga permasalahan remaja, terutama perilaku berisiko, perlu mendapatkan perhatian lebih.

Pemerintah melalui Badan Kependudukan dan Keluarga Berencana Nasional menyatakan bahwa, terdapat tiga risiko yang dihadapi oleh remaja, yaitu risiko yang berhubungan dengan seksualitas, NAPZA, HIV, dan AIDS. (Badan Kependudukan dan Keluarga Berencana Nasional, 2010). Ketiga risiko tersebut mendapat istilah Triad Kesehatan Reproduksi Remaja (KRR) yang berkaitan dengan hubungan seksual pranikah dan penyalahgunaan narkoba. Menurut Survei Demografi Kesehatan Indonesia (SDKI) 2017, sebanyak $8 \%$ pria dan $2 \%$ wanita pernah melakukan hubungan seks pra nikah. Sedangkan sebanyak $5 \%$ remaja laki-laki dan kurang dari $1 \%$ remaja perempuan di Indonesia pernah menggunakan obat-obatan terlarang (Badan Pusat Statistik (BPS), Badan Kependudukan dan Keluarga Berencana Nasional (BKKBN), Kementerian Kesehatan (Kemenkes), Measure DHS, \& ICF International, 2018). Meskipun prevalensi perilaku berisiko di atas termasuk rendah, hubungan seksual pranikah dan penyalahgunaan narkoba memiliki konsekuensi jangka panjang yang berat apabila tidak ditangani. Hubungan seks pranikah berkaitan dengan Kehamilan yang Tidak Diinginkan (KTD) dan penularan Infeksi Menular Seksual (Suwarni \& Selviana, 2015). Penyalahgunaan narkoba, khususnya yang berkaitan dengan penggunaan jarum suntik berkaitan dengan penularan penyakit HIVIAIDS (Nasution, Puspitawati, Risda, \& Puspitasari, 2019).

Green dan Kreuter (2005) menyatakan bahwa terdapat tiga faktor yang dapat memengaruhi seorang remaja untuk melakukan perilaku berisiko. Faktor pertama berkaitan dengan faktor dari dalam diri remaja (faktor predisposisi). Menurut penelitian yang telah dilakukan sebelumnya, umur lebih tua, laki-laki, pendidikan dan pengetahuan KRR yang rendah berkaitan dengan meningkatnya perilaku berisiko yang dilakukan remaja (Aghajni, Safa, Helli, \& Alizade, 2016; Anas, 2010; Mahdavian \& Zolala, 2017). Faktor kedua adalah faktor yang mendorong terlaksananya suatu perilaku (faktor enabling). Remaja yang bertempat tinggal di kota, status ekonomi rendah, dan memiliki akses yang kurang terhadap media informasi KRR berhubungan dengan meningkatnya perilaku berisiko (Anas, 2010; Badan Pusat Statistik (BPS) et al., 2013; Nasution et al., 2019). Faktor terakhir adalah faktor yang memperkuat suatu perilaku atau faktor reinforcing. Faktor penguat berasal dari pihak ketiga, adalah keluarga, guru, petugas kesehatan, atau teman. Komunikasi yang baik, hubungan yang harmonis, serta aturan yang diterapkan oleh orang tua berkaitan dengan pengaruh positif terhadap perilaku seksual. Sebaliknya, adanya konflik pada keluarga berhubungan dengan perilaku seks berisiko dan rendahnya kepatuhan remaja (Maimunah, 2013).

Berbagai penelitian mengenai perilaku remaja telah dilakukan di berbagai wilayah di Indonesia. Hasil penelitian yang dilakukan Hidayaningsih et al.(2011) di Makassar menunjukkan bahwa jenis kelamin, tingkat pendidikan, status pekerjaan, kebiasaan minum alkohol pada orang tua, dan kekerasan dalam rumah tangga (KDRT) berhubungan dengan perilaku berisiko pada remaja. Penelitian lain yang dilakukan oleh Maisya \& Susilowati (2014) di Keluarahan Kebon Kelapa menunjukkan bahwa umur, jenis kelamin, dan status pernikahan berkaitan dengan perilaku berisiko pada remaja berusia 15-24 tahun. Yulianingsih (2015) melakukan penelitian di Gorontalo didapatkan hubungan antara tindakan berisiko tertular HIVIAIDS (narkoba dan seks bebas) pada siswa SMA negeri dengan pengetahuan, sikap, religiusitas, keterpaparan media informasi, dan pengaruh teman sebaya.

Pada penelitian Lestary \& Sugiharti (2011) faktor enabling yang diteliti adalah tempat tinggal, status ekonomi, dan akses informasi, sedangkan faktor reinforcing yang diteliti adalah pendidikan kepala keluarga, komunikasi dengan orang tua, dan keberadaan teman yang berperilaku berisiko. Penelitian Hidayaningsih et al. (2011) tentang jumlah penghasilan sebagai faktor enabling serta kebiasaan minum alkohol dan KDRT sebagai faktor reinforcing. Maisya \& Susilowati (2014) hanya memasukkan sumber informasi sebagai faktor 
enabling tidak meneliti faktor reinforcing. Sementara itu, pada penelitian Yulianingsih(2015) faktor enabling yang diteliti adalah keterpaparan media, sedangkan faktor reinforcing yang diteliti adalah peran orang tua dan peran teman sebaya.

Penelitian di atas masih kurang komprehensif dalam meneliti faktor enabling dan reinforcing. Akan tetapi, pemerintah seperti BKKBN dan Kementerian Kesehatan (Kemenkes) sudah melaksanakan program yang berkaitan dengan remaja. Program tersebut dapat menjadi faktor enabling, yaitu terkait dengan akses terhadap media informasi, serta menjadi faktor reinforcing, terkait dengan program yang dibuat pemerintah yang ditujukan pada orang tua atau keluarga yang memiliki remaja. Pemerintah melalui BKKBN melaksanakan upaya pendidikan berbasis masyarakat melalui program ketahanan keluarga. Adapun kelompok ketahanan yang fokus pada pendidikan kesehatan reproduksi pada keluarga yang memiliki remaja adalah kelompok bina keluarga remaja (BKR). Sedangkan kelompok ketahanan lainnya seperti Usaha Peningkatan Pendapatan Keluarga Sejahtera (UPPKS), Pusat Pelayanan Keluarga Sejahtera (PPKS) atau lainnya, meskipun tidak fokus pada isu pendidikan keluarga remaja namun tetap memiliki aktivitas suplemensi bagi pengasuhan dan kesehatan reproduksi anggota keluarga, termasuk remaja. Belum ada data yang dikaitkan dengan perilaku berisiko pada remaja, padahal program pemerintah ini merupakan bagian dari faktor reinforcing. Dengan demikian, program ini kaitannya dengan perilaku berisiko perlu diteliti agar dapat dijadikan rujukan awal untuk mengevaluasi program-program tersebut secara lebih mendetail.

Berdasarkan uraian di atas, penelitian ini bertujuan untuk mengetahui faktor-faktor yang berhubungan dengan perilaku berisiko pada remaja di Jawa Barat tahun 2018. Perilaku berisiko pada remaja dalam hal ini meliputi perilaku seks pranikah (termasuk petting dan intercourse) dan penggunaan narkoba. Hasil penelitian ini diharapkan dapat memberikan gambaran terkini mengenai permasalahan kesehatan remaja di Jawa Barat, khususnya mengenai perilaku berisiko. Selain itu, diharapkan penelitian ini dapat dijadikan pertimbangan untuk membuat atau memperbaiki program dan kebijakan yang berkaitan dengan kesehatan remaja.

\section{METODE PENELITIAN}

Metode yang digunakan pada penelitian ini adalah metode analitik dengan pendekatan potong lintang. Penelitian ini menggunakan data sekunder dari Survei Kinerja dan Akuntabilitas Program Kependudukan, Keluarga Berencana, dan Pembangunan Keluarga tahun 2018 untuk Provinsi Jawa Barat. Penelitian ini telah mendapatkan izin etik dari BKKBN dengan No. 454/LB.02/H4/2019. Subjek pada penelitian ini adalah remaja laki-laki dan perempuan usia 15-24 tahun yang belum menikah pada unit keluarga. Variabel terikat pada penelitian ini adalah perilaku berisiko, yaitu pernah melakukan salah satu diantara perilaku seks pranikah (termasuk petting dan intercourse) dan mengonsumsi narkoba. Sedangkan variabel bebas pada penelitian ini terdiri dari faktor predisposisi, faktor enabling, dan faktor reinforcing. Faktor predisposisi merupakan faktor yang terkait pada diri remaja, yaitu umur, jenis kelamin, suku, tingkat pendidikan, aktivitas, dan pengetahuan remaja mengenai KRR. Faktor enabling merupakan faktor pendorong remaja dalam melakukan perilaku, yaitu klasifikasi tempat tinggal (pedesaan atau perkotaan), status ekonomi (kuintil kekayaan), dan sumber informasi KRR. Sedangkan faktor reinforcing merupakan faktor yang terkait dengan pihak ketiga, dalam penelitian ini adalah orang tua. Termasuk dalam faktor reinforcing adalah umur ayah dan ibu, pendidikan ayah dan ibu, pekerjaan ibu, paparan orang tua terhadap KRR dan pembangunan keluarga (PK), serta implementasi fungsi keluarga.

Data disajikan secara deskriptif dengan presentase, rata-rata dan standar deviasi, atau median dan nilai interquartile. Sedangkan analisis inferensial akan dilakukan uji regresi logistik bivariat untuk melihat hubungan antara setiap variabel independen dengan variabel dependen. Jika uji bivariat menunjukkan hasil yang signifikan $(p<$ $0,25)$, variabel bebas akan di analisis secara bersamaan menggunakan analisis regresi logistik multivariat untuk melihat hubungan variabel independen terhadap variabel dependen. Pada analisis multivariat, hubungan dinilai signifikan secara statistik apabila $p<0,05$. Seluruh tahapan analisis data dilakukan dengan IBM SPSS Statistics versi 24.

\section{HASIL DAN PEMBAHASAN}

Hasil penelitian ini menunjukkan bahwa remaja yang berperilaku berisiko sebanyak $6,02 \%$. Dari total 4573 responden sebesar $5,5 \%$ pernah melakukan hubungan seks pranikah, dan sebesar $4,5 \%$ pernah mengonsumsi narkoba. Tabel 1 menunjukkan hasil analisis bivariat dan multivariat faktor-faktor yang berhubungan dengan perilaku berisiko pada remaja di Jawa Barat. Berdasarkan analisis multivariat, variabel yang berhubungan 


\section{JKM (Jurnal Kebidanan Malahayati),Vol 7,No.2.April 2021, \\ ISSN (Print) 2476-8944 ISSN (Online) 2579-762X, Hal 177-184}

dengan perilaku berisiko adalah usia, jenis kelamin, pendidikan, klasifikasi daerah tempat tinggal, kuintil kekayaan (keluarga), indeks pengetahuan KRR, pengetahuan alat KB modern, jumlah sumber informasi KRR yang diketahui remaja dan orang tua, serta usia ibu. Remaja yang berusia 20-24 tahun, berjenis kelamin laki-laki, bertempat tinggal di daerah perkotaan, memiliki ibu yang berusia $\geq 60$ tahun memiliki risiko lebih tinggi dalam hal berperilaku berisiko. Sedangkan pendidikan menengah-tinggi dan semakin banyak terpapar sumber informasi KRR (remaja dan orang tua) berhubungan dengan penurunan perilaku berisiko. Semakin tinggi kuintil kekayaan, semakin berkurang risiko untuk melakukan perilaku berisiko, meskipun hubungan signifikan secara statistik hanya pada kuintil menengah bawah. Indeks KRR yang semakin baik dan semakin banyak mengetahui alat KB modern juga menurunkan risiko untuk melakukan perilaku berisko, meskipun pada indeks KRR hanya pada kategori sedang yang bermakna secara statistik.

Tabel 1.

Hubungan antara perilaku berisiko dengan faktor sosiodemografi, pengetahuan KRR dan fungsi keluarga, serta sumber informasi KRR dan pembangunan keluarga

\begin{tabular}{|c|c|c|c|c|}
\hline \multirow[b]{2}{*}{ Variabel } & \multicolumn{2}{|c|}{ Perilaku berisiko } & \multirow[b]{2}{*}{$\begin{array}{c}\text { Crude OR } \\
(95 \% \mathrm{Cl})\end{array}$} & \multirow[b]{2}{*}{$\begin{array}{l}\text { Adjusted OR } \\
(95 \% \mathrm{Cl})\end{array}$} \\
\hline & $\begin{array}{l}\text { Tidak } \\
\mathrm{n}(\%) \\
\end{array}$ & $\begin{array}{c}Y a \\
n(\%)\end{array}$ & & \\
\hline \multicolumn{5}{|l|}{ Usia (tahun) } \\
\hline $15-19$ & $2939(95,2)$ & $147(4,8)$ & referensi & Referensi \\
\hline $20-24$ & $1347(90,6)$ & $139(9,4)$ & $2,06(1,62-2,62)^{\star *}$ & $2,45(1,62-3,71)^{\star *}$ \\
\hline \multicolumn{5}{|l|}{ Suku } \\
\hline Sunda & $3284(94)$ & $209(6)$ & Referensi & \\
\hline Jawa & $653(92,6)$ & $52(7,4)$ & $1,24(0,91-1,70)$ & \\
\hline Lainnya & $349(93,3)$ & $25(6,7)$ & $1,14(0,74-1,74)$ & \\
\hline \multicolumn{5}{|l|}{ Jenis kelamin } \\
\hline Laki-laki & $2329(90,6)$ & $241(9,4)$ & $4,42(3,21-6,11)^{\star *}$ & $3,78(2,30-6,19)^{* *}$ \\
\hline Perempuan & $1957(97,7)$ & $46(2,3)$ & Referensi & Referensi \\
\hline \multicolumn{5}{|l|}{ Tingkat pendidikan remaja } \\
\hline Rendah & $1059(88,8)$ & $134(11,2)$ & Referensi & Referensi \\
\hline Menengah-tinggi & $3227(95,5)$ & $152(4,5)$ & $0,37(0,29-0,48)^{\star *}$ & $0,51(0,35-0,73)^{\star *}$ \\
\hline \multicolumn{5}{|c|}{ Klasifikasi daerah tempat tinggal } \\
\hline Perkotaan & $2972(93,3)$ & $213(6,7)$ & $1,28(0.972-1.68)^{*}$ & $2,63(1,67-4,13)^{\star *}$ \\
\hline Pedesaan & $1314(94,7)$ & $74(5,3)$ & Referensi & Referensi \\
\hline \multicolumn{5}{|l|}{ Kuintil kekayaan } \\
\hline Terbawah & $694(92,8)$ & $54(7,2)$ & Referensi & Referensi \\
\hline Menengah bawah & $750(95,2)$ & $38(4,8)$ & $0,65(0,42-0,99)^{*}$ & $0,38(0,20-0,71)^{* *}$ \\
\hline Menengah & $928(92,6)$ & $74(7,4)$ & $1,02(0,71-1,47)$ & $0,73(0,41-1,23)$ \\
\hline Menengah atas & $877(91,6)$ & $80(8,4)$ & $1,17(0,82-1,67)$ & $1,46(0,87-2,44)$ \\
\hline Teratas & $1037(96,4)$ & $39(3,6)$ & $0,48(0,31-0,73)^{* *}$ & $0,53(0,28-1,02)$ \\
\hline \multicolumn{5}{|l|}{ Aktivitas remaja } \\
\hline Bekerja & $1078(92,1)$ & $92(7,9)$ & $0,83(0,55-126)$ & Referensi \\
\hline Belum bekerja & $2874(94,7)$ & $161(5,3)$ & $0,55(0,37-0,81)^{\star *}$ & $1,02(0,66-1,57)$ \\
\hline Tidak bekerja & $333(90,7)$ & $34(9,3)$ & Referensi & $0,74(0,38-1,44)$ \\
\hline \multicolumn{5}{|l|}{ Usia ayah (tahun) } \\
\hline$<40$ & $262(96,3)$ & $10(3,7)$ & Referensi & Referensi \\
\hline $40-49$ & $1836(94,1)$ & $115(5,9)$ & $1,67(0,86-3,23)^{*}$ & $1,32(0,62-2,77)$ \\
\hline $50-59$ & $1315(92,3)$ & $109(7,7)$ & $2,20(1,13-4,28)^{\star *}$ & $0,89(0,38-2,03)$ \\
\hline$\geq 60$ & $479(92,3)$ & $40(7,7)$ & $2,23(1,09-4,54$ & $0,42(0,13-1,40)$ \\
\hline \multicolumn{5}{|l|}{ Usia ibu (tahun) } \\
\hline$<40$ & $878(94,2)$ & $54(5,8)$ & Referensi & Referensi \\
\hline $40-49$ & $2061(94,4)$ & $123(5,6)$ & $0,97(0,70-1,34)$ & $0,87(0,55-1,37)$ \\
\hline $50-59$ & $1058(94,6)$ & $60(5,4)$ & $0,93(0,64-1,35)$ & $1,18(0,61-2,27)$ \\
\hline$\geq 60$ & $119(88,8)$ & $15(11,2)$ & $2,11(1,16-3,83)^{* *}$ & $6,93(2,03-23,60)^{*}$ \\
\hline \multicolumn{5}{|l|}{ Status perkawinan orang tua } \\
\hline Menikah & $3806(93,6)$ & $259(6,4)$ & Referensi & \\
\hline Cerai & $471(94,6)$ & $27(5,4)$ & $0,86(0,57-1,28)$ & \\
\hline
\end{tabular}




\begin{tabular}{|c|c|c|c|c|}
\hline \multicolumn{5}{|l|}{ Tingkat pendidikan ayah } \\
\hline Rendah & $2468(93,6,9)$ & $182(6,4)$ & Referensi & \\
\hline Menengah-tinggi & $1244(93)$ & $93(7)$ & $1,09(0,84-1,41)$ & \\
\hline \multicolumn{5}{|l|}{ Tingkat pendidikan ibu } \\
\hline Rendah & $3074(93,7)$ & $208(6,3)$ & Referensi & Referensi \\
\hline Menengah-tinggi & $1042(95,9)$ & $45(4,1)$ & $0,64(0,46-0,88)^{* *}$ & $1,13(0,72-1,78)$ \\
\hline \multicolumn{5}{|l|}{ Pekerjaan ibu } \\
\hline Bekerja & $1138(93,7)$ & $77(6,3)$ & $1,14(0,87-1,51)$ & \\
\hline Tidak bekerja & $2978(94,4)$ & $176(5,6)$ & Referensi & \\
\hline \multicolumn{5}{|l|}{ Indeks pengetahuan KRR remaja } \\
\hline Buruk (0-59) & $2456(91,1)$ & $239(8,9)$ & Referensi & Referensi \\
\hline Sedang (60-79) & $1618(97,6)$ & $39(2,4)$ & $0,25(0,18-0,35)^{* *}$ & $0,43(0,27-0,66)^{* *}$ \\
\hline Baik $(\geq 80)$ & $212(96,4)$ & $8(3,6)$ & $0,38(0,18-0,78)^{* *}$ & $0,42(0,14-1,26)$ \\
\hline \multicolumn{5}{|l|}{$\begin{array}{l}\text { Pengetahuan remaja mengenai alat/cara KB } \\
\text { modern }\end{array}$} \\
\hline Tidak satupun & $220(91,7)$ & $20(8,3)$ & Referensi & Referensi \\
\hline 1-3 jenis & $1755(91,1)$ & $172(8,9)$ & $1,08(0,67-1,75)$ & $0,54(0,30-0,98)^{\star *}$ \\
\hline$\geq 3$ jenis & $2310(96)$ & $95(4)$ & $0,45(0,27-0,75)^{\star *}$ & $0,48(0,26-0,90)^{* *}$ \\
\hline \multicolumn{5}{|l|}{$\begin{array}{l}\text { Apakah orang tua aktif mengikuti kelompok } \\
\text { kegiatan BKR? }\end{array}$} \\
\hline Tidak & $2160(95,4)$ & $104(4,6)$ & - & \\
\hline Ya & $19(100)$ & $0(0)$ & - & \\
\hline \multicolumn{5}{|l|}{$\begin{array}{l}\text { Fungsi reproduksi: memberikan informasi } \\
\text { kesehatan reproduksi }\end{array}$} \\
\hline Tidak & $3113(93,3)$ & $224(6,7)$ & Referensi & Referensi \\
\hline Ya & $1164(94,9)$ & $62(5,1)$ & $0,74(0,56-0,99)^{\star *}$ & $1,07(0,73-1,57)$ \\
\hline \multicolumn{5}{|l|}{$\begin{array}{l}\text { Fungsi reproduksi: menghindari pergaulan } \\
\text { bebas }\end{array}$} \\
\hline Tidak & $1365(92,9)$ & $104(7,1)$ & Referensi & Referensi \\
\hline $\mathrm{Ya}$ & $2911(94,1)$ & $183(5,9)$ & $0,82(0,64-1,06)^{*}$ & $0,99(0,68-1,43)$ \\
\hline \multicolumn{5}{|l|}{$\begin{array}{l}\text { Fungsi cinta kasih: menunjukkan kasih } \\
\text { sayang }\end{array}$} \\
\hline Tidak & $1426(92,8)$ & $111(7,2)$ & Referensi & Referensi \\
\hline $\mathrm{Ya}$ & $2850(94,2)$ & $176(5,8)$ & $0,79(0,62-1,01)^{*}$ & $0,96(0,67-1,37)$ \\
\hline \multicolumn{5}{|l|}{ Fungsi perlindungan: perlindungan non-fisik } \\
\hline Tidak & $2516(93,4)$ & $177(6,6)$ & Referensi & \\
\hline $\mathrm{Ya}$ & $1760(94,1)$ & $110(5,9)$ & $0,89(0,69-1,13)$ & \\
\hline $\begin{array}{l}\text { Rerata jumlah sumber informasi KRR yang } \\
\text { diperoleh remajaa }\end{array}$ & $2,65+1,98$ & $2,17 \pm 1,65$ & $0,85(0,79-0,93)^{* *}$ & $0,89(0,79-0,99)^{* *}$ \\
\hline $\begin{array}{l}\text { Rerata jumlah sumber informasi KRR yang } \\
\text { diperoleh orang tua }{ }^{a}\end{array}$ & $1,99 \pm 1,79$ & $1,43 \pm 1,53$ & $0,76(0,67-0,86)^{\star *}$ & $0,86(0,75-0,99)^{* *}$ \\
\hline $\begin{array}{l}\text { Rerata jumlah sumber informasi PK yang } \\
\text { diperoleh orang tuab }\end{array}$ & $0,92 \pm 1,33$ & $0,63 \pm 1,15$ & $0,83(0,75-0,92)^{\star *}$ & $1,01(0,89-1,15)$ \\
\hline
\end{tabular}

*: p-value < 0,25;**: p-value < 0,05; a: koran, majalah, tabloid, pamflet, flipchart, poster, radio, televisi, internet/website, spanduk, banner, billboard, mural, pameran, dan mobil unit penerangan KB; b: BKR, Pusat Informasi dan Konseling Remaja (PIK-R), PPKS, dan UPPKS

\section{PEMBAHASAN}

Pada penelitian ini, proporsi remaja yang mengaku pernah melakukan perilaku berisiko sekitar $6 \%$, sebanyak $5,5 \%$ pernah melakukan hubungan seks pranikah, dan 4,5\% pernah mengonsumsi narkoba. Apabila dibandingkan denban negara lain, hasil ini juga tergolong rendah. Sebagai contoh, untuk remaja perempuan di Negara Etiopia sekitar 64\% memulai hubungan seksual sebelum 18 tahun, di antaranya 26\% dimulai sebelum usia 15 tahun (WHO and the Partnership for and Child Health, 2014). Terdapat kemungkinan bahwa hasil penelitian ini underreported karena pada negara seperti Indonesia, perilaku berisiko, terutama seks pranikah, bertentangan dengan adat ketimuran dan ajaran agama.

Hasil dari penelitian ini menunjukkan bahwa terdapat faktor predisposisi, meliputi usia, jenis kelamin, tingkat pendidikan, dan pengetahuan KRR. Sedangkan faktor pendorongnya adalah kuintil kekayaan dan klasifikasi tempat tinggal. Faktor penguat yang ditemukan yaitu usia ibu dan sumber informasi KRR yang pernah diperoleh orang tua. 
Hal ini sesuai dengan teori yang menyebutkan bahwa orang tua memiliki peran dalam pola asuh terhadap perilaku remaja, termasuk dalam hal perilaku berisiko (Mahdavian \& Zolala, 2017). Hasil penelitian ini sejalan dengan hasil penelitian yang dilakukan di Laos, yaitu terdapat perbedaan jenis kelamin dan usia, terhadap perilaku berisiko (Sychareun, Thomsen, \& Faxelid, 2011). Selain itu, penelitian di Afrika Selatan juga menemukan bahwa faktor individu dan kontekstual, seperti jenis kelamin, nilai orangtua anak, komunikasi orangtuaanak, keterikatan sekolah memengaruhi perilaku risiko seksual seperti seks seumur hidup, aktivitas seksual baru-baru ini, dan keterlibatan dengan banyak pasangan seksual (Amoateng, KaluleSabiti, \& Arkaah, 2014).

Perilaku berisiko lebih sering dilakukan oleh laki-laki karena remaja laki-laki memiliki pergaulan sosial dan kebebasan yang lebih luas, serta pengawasan oleh orang tua tidak seketat pada remaja perempuan (Aghajni et al., 2016). Selain itu, proporsi perilaku berisiko lebih sedikit ditemukan pada remaja perempuan yang disebabkan karena norma sosial yang berlaku bahwa menghindari perilaku berisiko merupakan bagian dari identitas gender sebagai perempuan. Sebaliknya, melakukan perilaku berisiko merupakan bagian dari identitas gender sebagai laki-laki (Booth \& Nolen, 2012). Umur yang lebih tua diasosiasikan dengan meningkatnya perilaku berisiko. Hal ini konsisten dengan penelitian lain yang menyebutkan bahwa terdapat hubungan antara umur remaja dan meningkatnya proporsi perilaku berisiko (Aghajni et al., 2016). Hal ini mungkin disebabkan oleh bertambah tua usia seorang remaja, pengawasan dari orang tua semakin berkurang, sementara pergaulan semakin luas (Mahmudah, Yaunin, \& Lestari, 2016).

Tingkat pendidikan remaja, kuintil kekayaan keluarga, klasifikasi tempat tinggal juga berhubungan dengan perilaku berisiko pada remaja, tetapi aktivitas remaja tidak berhubungan dengan perilaku berisiko. Hal tersebut disebabkan karena pendidikan berkaitan erat dengan pengetahuan seseorang kemauan untuk mencari informasi mengenai konsekuensi dari perilaku berisiko (Nasution et al., 2019). Meskipun pada penelitian ini terdapat hubungan signifikan yang hanya terjadi pada kuintil menengah bawah. Menurut Leão et al. (2017), penghasilan yang rendah sering dikaitkan dengan pendidikan yang rendah pula, sehingga akses untuk memiliki pengetahuan tentang perilaku berisiko juga rendah.

Tempat tinggal di perkotaan meningkatkan perilaku berisiko pada remaja, terkait dengan penggunaan narkoba. Hal tersebut, sesuai dengan studi yang dilakukan oleh Nasution et al (2019), dimana remaja di kota lebih rentan untuk menggunakan narkoba. Hal ini, disebabkan karena kemudahan mendapatkan narkoba di daerah perkotaan dibandingkan dengan daerah pedesaan. Pada remaja yang tinggal di perkotaan mendapatkan arus informasi mengenai seksualitas yang lebih banyak daripada di desa. Arus informasi ini, mendorong remaja untuk mencoba melakukan perilaku seks pranikah (Mahmudah et al., 2016).

Remaja dengan pengetahuan rendah dan hanya memiliki sumber informasi yang terbatas. Remaja yang memiliki pengetahuan dan sikap yang baik akan melakukan aktivitas yang positif, sehingga dapat terhindar dari perilaku berisiko (Wijaya, Agustini, \& MS, 2014). Hasil penelitian ini sejalan dengan hasil penelitian yang dilakukan di Jepara, didapatkan sebagian besar remaja memiliki pengetahuan kurang tentang kesehatan reproduksi. Oleh karena itu, diberikan pendidikan kesehatan reproduksi kepada remaja maka terdapat peningkatan pengetahuan remaja tentang kesehatan reproduksi (Widiyanto, Purnomo, \& Sari, 2013).

Remaja dengan ibu yang berusia lebih dari 60 tahun lebih berisiko untuk melakukan perilaku berisiko. Hal ini kemungkinan terkait dengan semakin bertambahnya usia ibu, semakin berkurangnya komunikasi dengan remaja dan semakin kurangnya paparan informasi terbaru mengenai pergaulan dan masalah KRR pada remaja. Untuk meningkatkan pengetahuan orang tua tentang pengasuhan anak yang baik dan pentingnya menjaga keharmonisan di rumah, disarankan orang tua untuk mengikuti seminar tentang mendidik anak, sehingga anak merasa nyaman, agar dapat mengurangi perilaku berisiko pada remaja (Hidayangsih et al., 2011). Remaja sebaiknya memiliki sumber informasi mengenai pubertas dan seksual dari ibu dan ayah selain dari berbagai sumber dan pelajaran formal di sekolah (Kamrani et al., 2011). Informasi tersebut dapat tersampaikan ketika terdapat komunikasi antara orang tua dengan remaja akan memberikan dampak terhadap perilaku remaja. Oleh karena itu, diperlukan program-program edukasi mengenai kesehatan reproduksi pada remaja (Hindin \& Fatusi, 2009).

Status perkawinan orang tua, pendidikan orang tua, dan pekerjaan orang tua pada penelitian ini tidak berkaitan dengan perilaku risiko pada remaja, hasil ini sejalan dengan penelitian yang dilakukan oleh Maimunah (2013). Akan tetapi, hasil ini berbeda dengan hasil penelitian Kao dan Carter 


\section{JKM (Jurnal Kebidanan Malahayati),Vol 7,No.2.April 2021, ISSN (Print) 2476-8944 ISSN (Online) 2579-762X, Hal 177-184}

(2013) yang menunjukkan bahwa memiliki orang tua lengkap dan berpendidikan tinggi berhubungan dengan pengendalian perilaku seksual pada remaja. Perbedaan ini mungkin terjadi karena pada penelitian ini terdapat homogenitas dalam hal tingkat pendidikan dan status perkawinan orang tua.

Seiring dengan perkembangan zaman, kini media massa memiliki peranan penting dalam proses transformasi nilai dan norma baru bagi masyarakat. Seperti yang dijelaskan dalam penelitian Elizabeth Noelle-Nuemann (2008), opini publik yang terbentuk dalam merespon suatu isu sangat ditentukan oleh faktor media. Dalam konteks pengasuhan remaja, media massa juga berpengaruh signifikan terhadap kecenderungan kenakalan remaja (Sriyanto, Abdulkarim, Zainul, \& Maryani, 2014). Setelah para remaja membaca media, mereka cenderung menunjukkan perubahan dirinya. Perubahan tersebut meliputi aspek kognitif, afektif dan behavioural. Aspek kognitif berhubungan dengan durasi membaca konten, sedangkan aspek afektif dan behavioural berhubungan dengan pemilihan jenis konten/rubrik yang dibaca atau diakses (Astiwi, 2007). Hal ini sejalan dengan teori belajar social dari Bandura (1989) yang mendasarkan bahwa perilaku ditentukan oleh lingkungan dan dapat dipelajari dengan membentuk asosiasi yang terjadi karena kebiasaan dan paparan yang berulang (Kurniadi, 2001). Dengan demikian, peran media massa penting untuk memberikan edukasi mengenai KRR baik pada remaja maupun orang tua.

Fungsi keluarga sangat penting dalam membentuk perilaku remaja. Ketika keluarga tidak dapat menjalankan fungsinya dengan baik, remaja akan merasakan kebingungan peran atau yang disebut dengan role confusion yang kemudian akan menimbulkan permasalahan (Schwartz, Pantin, Prado, Sullivan, \& Szapocznik, 2005). Selain itu, kontrol orang tua dalam artian adanya komunikasi yang baik, adanya penerapan aturan, dan relasi harmonis juga akan memberikan pengaruh yang baik terhadap perilaku remaja. Orang tua sebaiknya tidak menganggap tabu hal-hal terkait fungsi reproduksi, agar remaja tidak mencari informasi mengenai KRR dari sumber yang tidak tepat (Maimunah, 2013).

Penelitian ini memiliki keterbatasan, yaitu terdapat pengambilan data yang berisfat sensitif, berupa rasa percaya responden belum dapat terbangun karena responden dan surveyor bertemu hanya satu kali. Selain itu juga, saat responden mengisi kuesioner, responden berada pada sekitar keluarga sehingga memungkinkan adanya rasa takut dan khawatir dalam memberikan jawaban yang akurat.

\section{SIMPULAN}

Simpulan dalam penelitian ini adalah faktorfaktor yang memengaruhi perilaku berisiko pada remaja terdiri dari faktor predisposisi yang berasal dari diri remaja, yaitu usia, jenis kelamin, tingkat pendidikan, dan pengetahuan KRR; faktor pendorong, yaitu kuintil kekayaan dan klasifikasi tempat tinggal; faktor penguat, yaitu usia ibu dan sumber informasi KRR yang pernah diperoleh orang tua.

\section{SARAN}

Mengingat konsekuensi jangka panjang dari perilaku berisiko, maka pemerintah perlu menginisiasi dan memperbaiki program yang berkaitan dengan KRR. Adapun strategi yang dibuat dengan mempertimbangkan faktor pengetahuan mengenai KRR. Dalam praktiknya substansi KRR perlu ditingkatkan dan diintegrasikan pada kurikulum pendidikan formal. Dimulai pada jenjang pendidikan sekolah dasar sampai dengan universitas. Selian itu, materi pendidikan KRR dibuat spesifik berdasarkan jenis kelamin. Adapun metode penyampaian pesan pada remaja dapat memanfaatkan media massa, seperti media elektronik (radio dan televisi) dan media internet. Sementara itu, media yang paling sering diakses oleh orang tua adalah media elektronik. Pendidikan KRR berisi konten yang memotivasi orang tua agar tidak tabu dalam mendiskusikan isu seksualitas dengan seluruh anggota keluarga termasuk anak.

\section{UCAPAN TERIMA KASIH}

Penelitian ini mendapatkan hibah kerjasama dengan Badan Kependudukan dan Keluarga Berencana Nasional (BKKBN).

\section{DAFTAR PUSTAKA}

Aghajni, M., Safa, A., Helli, E., \& Alizade, M. (2016). High-Risk behaviors and their relationship with demographic characteristic in girl and boy adolescents. Journal of Research and Health, 6(5), 471-478. https://doi.org/10.18869/acadpub.jrh.6.5.471

Amoateng, A. Y., Kalule-Sabiti, I., \& Arkaah, Y. J. (2014). The effect of socio-demographic factors on risky-sexual behaviours of adolescents in the North West Province of South Africa. Etude de La Population Africaine, 28(1), 487-498. https://doi.org/10.11564/28-1-502 
Anas, S. H. (2010). Sketsa kesehatan reproduksi remaja. Jurnal Studi Gender \& Anak, 5(1), 199-214. https://doi.org/10.1016/S15724352(06)02002-2

Astiwi, H. (2007). Pola membaca majalah remaja dan pengaruhnya terhadap perilaku remaja (Kasus siswa Sekolah Menengah Umum Negeri 2 Bogor, Provinsi Jawa Barat). (Skripsi tidak dipublikasikan). Prodi Komunikasi dan Pengembangan Masyarakat Fakultas Pertanian IPB.

Badan Kependudukan dan Keluarga Berencana Nasional. (2010). Pendewasaan usia perkawinan dan hak-hak reproduksi bagi remaja Indonesia. Jakarta: BKKBN.

Badan Kependudukan dan Keluarga Berencana Nasional. (2011). Kajian Profil penduduk Remaja (10-24 tahun): Ada apa dengan remaja. Jakarta: Puslitbang kependudukanBKKBN.

Badan Pusat Statistik (BPS), Badan Kependudukan dan Keluarga Berencana Nasional (BKKBN), Kementerian Kesehatan (Kemenkes), Measure DHS, \& ICF International. (2018). Survei Demografi dan Kesehatan Indonesia tahun 2017, Kesehatan Reproduksi Remaja. Jakarta.

Bandura, A. (1989). Social cognitive theory. In R. Vasta (Ed.), Annals of child development. Vol. 6. Six theories of child development (pp. 1-60). Greenwich, CT: JAI Press.

Booth, A. L., \& Nolen, P. (2012). Gender differences in risk behaviour: Does nurture matter? Economic Journal, 122(558), 56-78. https://doi.org/10.1111/j.1468-

0297.2011.02480.x

Green, L. W., \& Kreuter, M. W. (2005). Health program planning: an educational and ecological approach (4th ed.). New York: McGraw-Hill.

Hidayangsih, P. S., Tjandarini, D. H., Mubasyiroj, R., \& Supanni, S. (2011). Faktor-Faktor yang berhubungan dengan perilaku berisiko remaja di Kota Makassar tahun 2009. Buletin Penelitian Kesehatan, 39(2), 88-98.

Hindin, M. J., \& Fatusi, A. O. (2009). Adolescent sexual and reproductive health in developing countries: An overview of trends and interventions. International Family Planning Perspectives.

https://doi.org/10.1363/3505809

Kamrani, M.A., Sharifah Zainiyah S.Y., Hamzah A., \& Ahmad Z. (2011). Source of Information on Sexual and Reproductive Health Among Secondary Schools ' Girls in the Klang
Valley. Malaysian Journal of Public Health Medicine, 11(1), 29-35.

Kao, T.-S. A., \& Carter, W. A. (2013). Family Influences on Adolescent Sexual Activity and Alcohol Use. The Open Family Studies Journal, $\quad 5(1)$, 10-18. https://doi.org/10.2174/18749224013050100 10

Kurniadi, O. (2001). Pengaruh Komunikasi Keluarga terhadap Prestasi Belajar Anak. Mediator, 2(2), 267-290.

Leão, A. S., Moura Soares, N. M., Gonçalves, E. C. D. A., Silva, D. A. S., Silva, R. J. D. S., \& Thomazzi, S. M. (2017). Simultaneous health risk behaviors in adolescents associated with higher economic class in the Northeast of Brazil. Scientific World Journal, 2017, 1-8. https://doi.org/10.1155/2017/3587567

Lestary, H., \& Sugiharti, S. (2011). Perilaku Berisiko Remaja Di Indonesia Menurut Survey Kesehatan Reproduksi Remaja Indonesia (Skrri) Tahun 2007. Jurnal Kesehatan Reproduksi, 1(3), 136-144. https://doi.org/10.22435/jkr.v1i3Agt.1389.136 $-144$

Mahdavian, M., \& Zolala, F. (2017). Determinants of risky behaviors in youth: A gender-based study. International Journal of High Risk Behaviors and Addiction, 6(1), 1-9. https://doi.org/10.5812/ijhrba.23604

Mahmudah, Yaunin, Y., \& Lestari, Y. (2016). Faktorfaktor yang berhubungan dengan perilaku seksual remaja di Kota Padang. Jurnal FK Unand, 5(2), 448-455.

Maimunah, S. (2013). Pengaruh faktor keluarga terhadap perilaku seksual remaja. Artikel dipresentasikan pada Seminar Psikologi \& Kemanusiaan, Malang.

Maisya, I. B., \& Susilowati, A. (2014). Faktor pada remaja muda dan tersedianya media informasi jubungannya dengan perilaku berisiko. Pusat Teknologi Intervensi Kesehatan Masyarakat Badan LitBangKes, Kementrian Kesehatan, 5(3), 1-7.

Nasution, S. L., Puspitawati, H., Risda, R., \& Puspitasari, M. D. (2019). Pengaruh pengetahuan remaja tentang NAPZA dan HIV serta pengetahuan orang tua tentang program pembangunan keluarga terhadap perilaku penggunaan NAPZA pada remaja. Jur. IIm. Kel. \& Kons., 12(2), 100-113.

Schwartz, S. J., Pantin, H., Prado, G., Sullivan, S., \& Szapocznik, J. (2005). Family functioning, identity, and problem behavior in hispanic 
JKM (Jurnal Kebidanan Malahayati),Vol 7,No.2.April 2021,

ISSN (Print) 2476-8944 ISSN (Online) 2579-762X, Hal 177-184

immigrant early adolescents. Journal of Early Adolescence.

https://doi.org/10.1177/0272431605279843

Sriyanto, Abdulkarim, A., Zainul, A., \& Maryani, E. (2014). Perilaku asertif dan kecenderungan kenakalan remaja berdasarkan pola Asuh dan peran media massa. Jurnal Psikologi, 41(1), 74. https://doi.org/10.22146/jpsi.6959

Suwarni, L., \& Selviana, S. (2015). Inisiasi seks pranikah remaja dan faktor yang mempengaruhi. KEMAS, 10(2), 169-177.

Sychareun, V., Thomsen, S., \& Faxelid, E. (2011). Concurrent multiple health risk behaviors among adolescents in Luangnamtha province, Lao PDR. BMC Public Health, 11, 1-10. https://doi.org/10.1186/1471-2458-1136

WHO and the Partnership for and Child Health.
(2014). National Reproductive Health Strategy 2014-2018. Geneva.

Widiyanto, B., Purnomo, \& Sari, A. M. (2013). Pengaruh pemberian pendidikan kesehatan reproduksi remaja terhadap pengetahuan tentang perilaku seksual. Jurnal Keperawatan Komunitas, 1(2), 101-107.

Wijaya, I. M. K., Agustini, N. N. M., \& MS, G. D. T. (2014). Pengetahuan, sikap dan aktivitas remaja SMA dalam kesehatan reproduksi di Kecamatan Buleleng. KESMAS - Jurnal Kesehatan Masyarakat, 10(1), 33-42. https://doi.org/10.15294/kemas.v10i1.3068

Yulianingsih, E. (2015). Faktor-faktor yang berhubungan dengan tindakan berisiko tertular HIV I AIDS pada siswa SMA Negeri di Kota Gorontalo. JIKMU, 5(2a), 311-321. 